\title{
A re-evaluation of diastatic Saccharomyces cerevisiae strains and their role in brewing
}

\author{
Kristoffer Krogerus $^{1}$ (D) Brian Gibson $^{1}$
}

Received: 4 February 2020 / Revised: 2 March 2020 / Accepted: 5 March 2020 / Published online: 13 March 2020

(C) The Author(s) 2020

\begin{abstract}
Diastatic strains of Saccharomyces cerevisiae possess the unique ability to hydrolyze and ferment long-chain oligosaccharides like dextrin and starch. They have long been regarded as important spoilage microbes in beer, but recent studies have inspired a re-evaluation of the significance of the group. Rather than being merely wild-yeast contaminants, they are highly specialized, domesticated yeasts belonging to a major brewing yeast lineage. In fact, many diastatic strains have unknowingly been used as production strains for decades. These yeasts are used in the production of traditional beer styles, like saison, but also show potential for creation of new beers with novel chemical and physical properties. Herein, we review results of the most recent studies and provide a detailed account of the structure, regulation, and functional role of the glucoamylase-encoding STA1 gene in relation to brewing and other fermentation industries. The state of the art in detecting diastatic yeast in the brewery is also summarized. In summary, these latest results highlight that having diastatic $S$. cerevisiae in your brewery is not necessarily a bad thing.
\end{abstract}

\section{Key Points}

-Diastatic S. cerevisiae strains are important spoilage microbes in brewery fermentations.

- These strains belong to the 'Beer 2' or 'Mosaic beer' brewing yeast lineage.

-Diastatic strains have unknowingly been used as production strains in breweries.

-The STA1-encoded glucoamylase enables efficient maltotriose use.

Keywords Yeast $\cdot$ Beer $\cdot$ Dextrin $\cdot$ Starch $\cdot$ Diastatic $\cdot$ Genome

\section{Introduction}

Diastatic strains of Saccharomyces cerevisiae are an important group of spoilage microbes in industrial beer fermentations. These yeasts, in contrast to other $S$. cerevisiae strains, are capable of producing an extracellular glucoamylase enzyme that enables fermentation on oligosaccharides and starch if

Electronic supplementary material The online version of this article (https://doi.org/10.1007/s00253-020-10531-0) contains supplementary material, which is available to authorized users.

Kristoffer Krogerus

kristoffer.krogerus@gmail.com

1 VTT Technical Research Centre of Finland Ltd, Tietotie 2, P.O. Box 1000, FI-02044 VTT Espoo, Finland present. If these diastatic strains contaminate beer, they are able to release glucose from the non-reducing end of any residual oligosaccharides, which in turn leads to extended fermentation. This can have numerous negative effects on the beer, including increased carbon dioxide and ethanol levels, drier mouthfeel, and production of off-flavor, particularly the clove-like 4-vinyl guaiacol. In extreme cases, this can lead to gushing and exploding packages, endangering the consumer. Instances of contamination by diastatic yeast in commercial breweries have been reported in the USA and across Europe, and they appear to have increased in recent years (Begrow 2017; Meier-Dörnberg et al. 2017). Contaminations in the bottling area were the most common in a recent survey (Meier-Dörnberg et al. 2017). Smaller breweries in particular tend to be more susceptible to contamination, as beers are seldom pasteurized, quality control is less stringent, and experimentation with different yeast strains is more common. 
Extracellular glucoamylolytic activity in yeast was observed already in the 1940s (Bishop and Whitley 1943), while the first isolation of a diastatic Saccharomyces strain was reported in 1952 (Andrews and Gilliland 1952). The authors proposed the taxonomic name Saccharomyces diastaticus and justified its classification as a separate species based on its unique phenotypic property (Gilliland 1966). Later, however, S. diastaticus was designated $S$. cerevisiae (as var. diastaticus) based on its ability to interbreed and produce fertile hybrids with $S$. cerevisiae (Tamaki 1978). This classification has now been confirmed by whole-genome sequencing (Liti et al. 2009; Peter et al. 2018). Despite this, the name S. diastaticus is still commonly used, particularly in the brewing industry. Interestingly, using data from recent largescale whole-genome sequencing studies (Gallone et al. 2016; Peter et al. 2018), it has been revealed that diastatic $S$. cerevisiae contaminants belong to a lineage of brewing yeast strains (the 'Beer 2' or 'Mosaic beer' group) and many diastatic $S$. cerevisiae strains are intentionally used as production strains (Krogerus et al. 2019).

The extracellular glucoamylase associated with diastatic S. cerevisiae is encoded by the STA genes (Tamaki 1978; Yamashita et al. 1985a, b). A number of highly homologous genes, STA1-STA3, have been described (Tamaki 1978; Yamashita et al. 1985b; Lambrechts et al. 1991). The DNA sequences of these genes are nearly identical, but they were given different names as they were located on different chromosomes and linkage groups (Tamaki 1978). Using pulsedfield gel electrophoresis, STA genes have been identified on chromosomes II, IV, and XIV (Pretorius and Marmu 1988; Bignell and Evans 1990). In addition to these, long-read sequencing data also suggests that STAl can be found on chromosomes IX and X, in the $S$. cerevisiae A-81062 and WLP570 'Beer 2' strains, respectively (Krogerus et al. 2019). Genome assemblies from the same long-read sequencing data reveal that STA1 is located in the subtelomeric regions. These regions are known to be dynamic and unstable and are susceptible to structural rearrangements and reshuffling (Brown et al. 2010; Yue et al. 2017). In addition to $S T A$, the names DEX1 and DEX2 have been used to describe genes encoding extracellular glucoamylases in diastatic $S$. cerevisiae, but these were shown to be allelic to the STA genes (Erratt and Stewart 1981; Erratt and Nasim 1986). The name STA1 will be used throughout the rest of this minireview to address the gene(s) encoding the extracellular glucoamylase in diastatic $S$. cerevisiae.

\section{Structure and formation of the STA1 gene}

After the gene responsible for the diastatic phenotype was discovered, it was revealed that STA1 appeared to be chimeric (Fig. 1a), resulting from the fusion of FLO11 and
SGAl (Yamashita et al. 1987; Lo and Dranginis 1996). These genes are located on opposite ends of chromosome IX in S. cerevisiae. The $3^{\prime}$ end of STA1 is homologous to $S G A 1$, a gene encoding an intracellular glucoamylase that is used during sporulation. The catalytic domain of STA1 is located in this SGAl-derived peptide (Adam et al. 2004). The $5^{\prime}$ end of STA1, along with the upstream region, are homologous to FLO11, a gene encoding a membrane-bound flocculin promoting flocculation. This FLO11-derived peptide allows for extracellular secretion of the STA1-encoded glucoamylase (Adam et al. 2004). As the upstream regions of STA1 and FLO11 are nearly identical as well, these two genes are largely co-regulated (Gagiano et al. 1999). The sequence around the FLO11/ SGA1 junction in STA1 contains three short homologous blocks (Yamashita et al. 1987). In particular, two 8-bp stretches at the junction are shared between FLO11 and $S G A 1$ (Fig. 1b). Gene fusion appears to be a result of a non-reciprocal translocation, as chromosome IX in longread genome assemblies of STA1+ strains appears collinear with chromosome IX of $S$. cerevisiae S288C (Krogerus et al. 2019). Such a translocation could arise from repair of a double-stranded break by recombination mediated by the homologous blocks in FLO11 and SGA1, as has been proposed for gene fusion events that have been observed in laboratory evolution experiments (Dunn et al. 2013; Brouwers et al. 2019).

The catalytic domain of Sta1p is located in the SGA1-derived peptide. The $S G A 1$-encoded glucoamylase is involved in releasing glucose from glycogen during sporulation (François and Parrou 2001). It has also been shown to hydrolyze starch (Pugh et al. 1989). The three-dimensional structure of the Stalp glucoamylase has not been determined, but a structural model, based on the known structure of a similar glucoamylase from Saccharomycopsis fibuligera, suggests that the catalytic domain has a $(\alpha / \alpha)_{6}$ barrel structure, with the active site being comprised of two catalytic glutamic acid residues (E521 and E770) (Adam et al. 2004). In contrast to many other fungal glucoamylases, the Stalp glucoamylase lacks a starch-binding domain and is thus only active on soluble starch (Sauer et al. 2000; Adam et al. 2004; LatorreGarcía et al. 2005).

The extracellular secretion of the STA1-coded glucoamylase is enabled by the FLO11-derived sequence. The first 32 amino acids of the amino-terminal end of Stalp form a hydrophobic leader peptide (Yamashita et al. 1985b; Yamashita et al. 1987), which when removed hinders secretion of Stalp (Yamashita 1989) and when fused to other enzymes allows their secretion (Yamashita et al. 1986; Vanoni et al. 1989). In addition to the signal peptide, the Stalp sequence contains a serine- and threonine-rich region which provides multiple $O$-glycosylation sites (Yamashita 1989; Adam et al. 2004). Indeed, the 


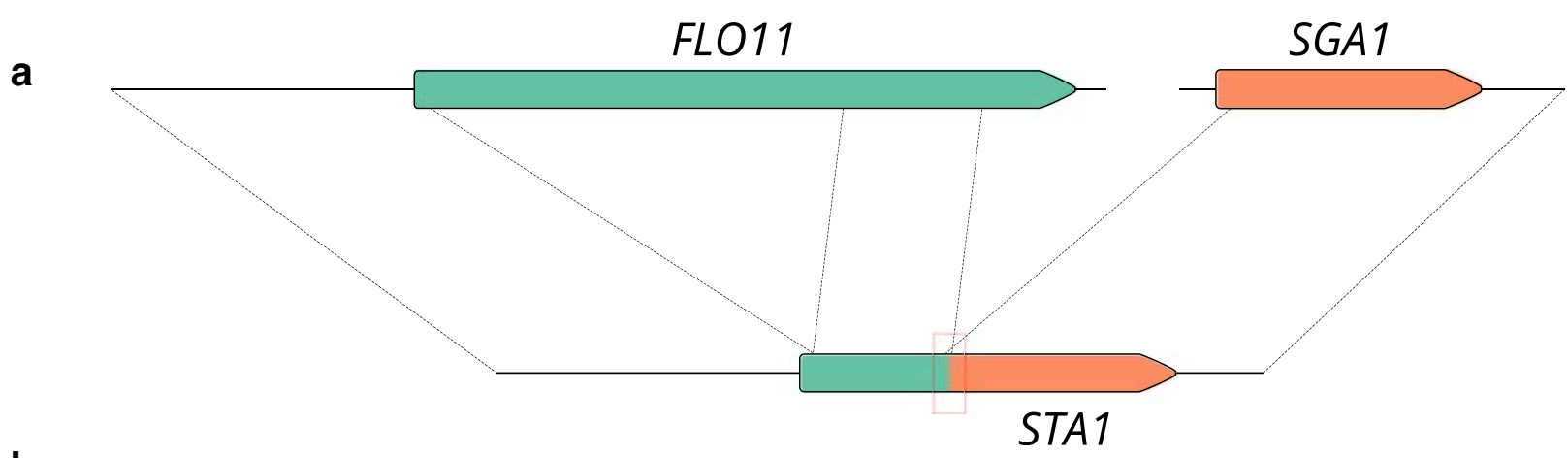

b

FLO11:3450 to 3540 GGGTACTAACTCCGCTGGTAAGACGACACTGGTTACACAACAAAGTCTGTACCAACCACCTATGTACC-ACTITGGC---

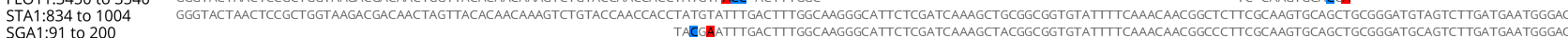

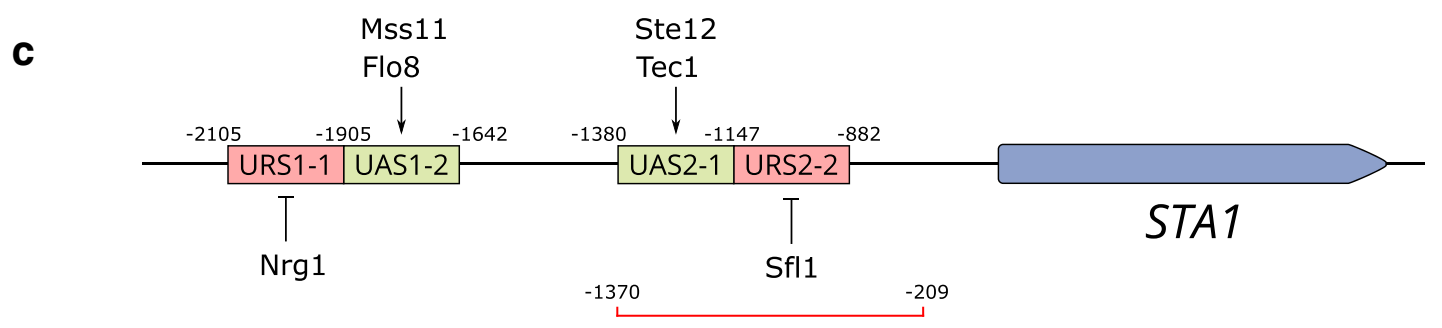

Deletion in STA1 promoter

Fig. 1 a The structure of STAI and homology to ancestral genes FLO11 and $S G A 1$. The FLO11/SGA1 junction is highlighted with a red box, and the sequence is shown in panel $\mathbf{B}$. The illustration is drawn to scale. $\mathbf{b}$ Multiple sequence alignment of the nucleotide sequence around the FLO11/SGA1 junction in STA1 (X02649.1 in the NCBI-Nucleotide database) with FLO11 and SGA1. Colors indicate mutations in comparison with the STA1 sequence. c The structure of the STA1 promoter. Upstream

STA1-derived glucoamylase is highly glycosylated, as protein masses of 250-300 kDa have been reported (Modena et al. 1986; Kleinman et al. 1988; Adam et al. 2004). The estimated size of the Stalp amino acid sequence is approximately $83 \mathrm{kDa}$ (Adam et al. 2004). The serine- and threonine-rich region has also been proposed to facilitate secretion of the glucoamylase, as partial and full deletion of this region reduces glucoamylolytic activity and the amount of glucoamylase detected in the culture media (Yamashita 1989; Adam et al. 2004). However, the signal peptide appears to have the larger role in enabling secretion (Marín-Navarro et al. 2011). The hyperglycosylation of Stalp could potentially influence enzyme activity as well, e.g., by stabilizing the enzyme structure (Solovicova et al. 1999), as lower culture media glucoamylase activities were observed from a mnn 9 mutant with reduced glycosylation (Adam et al. 2004). However, it remained unclear whether the decrease in activity was a result of decreased secretion to the media or decreased specific enzyme activity. activating sequences (UAS1-2 and UAS2-1) are shown with green boxes, and the respective activator proteins are shown above the boxes. Upstream repressing sequences (URS1-1 and URS2-2) are shown with red boxes, and the respective repressor proteins are shown below the boxes. The location of the 1162-bp deletion in the STA1 promoter, which is common in many STAI+ strains, is highlighted with the red line. The illustration is not drawn to scale

\section{Regulation of STA1 transcription}

The promoter regions of STA1 and FLO11 are very similar. The expression of these two genes is therefore induced and repressed in similar environmental conditions. The promoters of STA1 and FLO11 are complex (Fig. 1c), covering over 2.5$\mathrm{kbp}$ and containing multiple regulatory regions; indeed, they are one of the largest promoters in $S$. cerevisiae (Rupp et al. 1999; Kim et al. 2004a, b; Barrales et al. 2008). The STA1 promoter contains at least two segments controlling expression, UAS1 and UAS2 (Kim et al. 2004a, b). Both can be further divided into an upstream activating sequence (UAS) and upstream repressing sequence (URS); UAS1-2 and URS1-1, respectively, for UAS1, and UAS2-1 and URS2-2, respectively, for UAS2. Each of these four segments contain transcription factor binding sites. The repressors $\mathrm{Nrg} 1$ and Sfl1 bind to URS1-1 and URS2-2, respectively, while the activators Mss11 and Flo8 bind to UAS1-2, and activators Ste12 and Tec1 bind to UAS2-1 (Kim et al. 2004a, b) (Fig. 
1c). It has been proposed that these activators bind sequentially to the promoter to enable transcription, and bound repressors prevent their binding to the UASs.

Control of STA1 (and FLO11) expression is therefore complex and appears to rely on the balance of numerous transcription factors. These transcription factors are also involved in other cellular processes. Flo8, for example, is regulated by the cAMP-PKA pathway (Pan and Heitman 1999), while Ste12 and Tec1 are involved in the MAP kinase pathway (Madhani 1997). As a result of this complexity, FLO11 expression has been used as a model for studying how signaling pathways affect gene expression (Vinod et al. 2008; Octavio et al. 2009; Brückner and Mösch 2012). Early studies on the regulation of STA1, also identified an apparent repressor that was designated STA10 (Polaina and Wiggs 1983; Pardo et al. 1986). However, later studies revealed that $S T A 10$ was just a non-functional allele of the activator-encoding FLO8 (Kim et al. 2003). Early studies on STA1 regulation also revealed an apparent effect of ploidy, with higher levels of STA1 expression in haploid strains compared with diploid strains (Pretorius et al. 1986; Dranginis 1989). It was hypothesized that the a $1 / \alpha 2$ heterodimer that forms in $\mathrm{MATa} / \mathrm{MAT} \alpha$ cells, could repress STA1, but no evidence of direct repression has been observed (Lambrechts et al. 1994). Rather, it is likely that a1/ $\alpha 2$ heterodimer can indirectly affect STA1 expression by influencing the transcription factors. Ste12, one of the activators, for example, is upregulated in the presence of $\alpha$-pheromone (Brückner and Mösch 2012; Cullen and Sprague 2012). Interestingly, a number of the STA1+ 'Beer 2' strains (see Supplementary Fig. S1) appear to be haploid based on homozygosity and HO deletion (Peter et al. 2018). These haploid strains likely show an increased diastatic activity.

In regard to environmental factors affecting STA1 expression, the presence of glucose has been shown to repress transcription (Pretorius et al. 1986; Dranginis 1989; Kim et al. 2004b). This appears to be partly mediated by increased levels of the $\mathrm{Nrg} 1$ and $\mathrm{Sfl} 1$ repressors resulting from growth on glucose (Kim et al. 2004b). When a STA1+ strain was grown in rich media containing various carbon sources, the highest STA1 mRNA levels were measured in complex media containing glycerol and ethanol, followed by those containing starch or a mixture of maltooligosaccharides (Pretorius et al. 1986). Starch therefore does not induce expression, as was also confirmed in a later study (Dranginis 1989). STA1 expression was considerably lower in media containing glucose or sucrose, but results show that glucose does not completely inhibit STA1 expression (Pretorius et al. 1986; Dranginis 1989). In brewery fermentation trials, glucoamylase activity was detected in the wort after $20 \mathrm{~h}$, with an increase in activity as fermentation progressed (Searle and Tubb 1981). During wort fermentations with $S T A 1+$ strains, in contrast to STA1-negative brewing strains, low concentrations of glucose are present throughout most of the active fermentation as a result of the amylolytic activity (Searle and Tubb 1981; Krogerus et al. 2019). It is likely that this continuous supply of glucose to diastatic yeast can considerably influence the yeast transcriptome in comparison with STA1-negative brewing strains, as many fermentation-related genes, e.g., maltose permeases, are repressed by glucose (Day et al. 2002).

A recent study (Krogerus et al. 2019) revealed that many of the diastatic $S$. cerevisiae strains that were screened had a 1162-bp deletion in the promoter of STA1 (Fig. 1c). This deleted region contains the UAS2-1 activating sequence with binding sites for the Ste12 and Tec1 transcription factors (Kim et al. 2004a). The presence of this deletion significantly decreased the expression of STA1 (over 100-fold) and the ability to grow in beer and consume dextrin (Krogerus et al. 2019; Burns et al. 2020). Therefore, not all STA1+ strains have the same spoilage potential, and detection of the gene itself is not a reliable marker for beer spoilage potential. Detection methods for diastatic $S$. cerevisiae are discussed in more detail below.

\section{Functional role of STA1}

Thanks to the glucoamylolytic activity of diastatic yeast, they have a competitive advantage compared with traditional brewing strains in dextrin- or starch-rich environments where concentrations of fermentable carbon sources are low. Beer is a prime example of such an environment, and most STA1+ strains, in contrast to ale or lager strains, are able to grow and produce carbon dioxide in fermented beer (Meier-Dörnberg et al. 2018; Krogerus et al. 2019). In addition to longer chain carbohydrates, Sta1p efficiently hydrolyzes maltotriose and other maltooligomers (Modena et al. 1986; Kleinman et al. 1988). Early wort fermentation trials with diastatic $S$. cerevisiae already hinted towards a role for Sta1p in maltotriose use, as maltotriose was depleted from the wort more quickly with diastatic strains compared with an ale brewing strain (Searle and Tubb 1981).

As discussed in the Introduction, the STA1 gene is prevalent in the 'Beer 2' or 'Mosaic beer' lineage of S. cerevisiae (Fig. 2) (Gallone et al. 2016; Peter et al. 2018; Krogerus et al. 2019). This lineage consists of strains isolated from and used in breweries. The other main lineage of brewing yeasts is the 'Beer 1' or 'Ale beer' lineage (Gallone et al. 2016; Gonçalves et al. 2016; Peter et al. 2018). The majority of the sequenced strains belonging to the 'Beer 2' lineage carry the STA1 gene (Krogerus et al. 2019). These strains, like most brewing strains, have been shown to utilize maltotriose efficiently (Gallone et al. 2016). However, the mechanism for maltotriose 


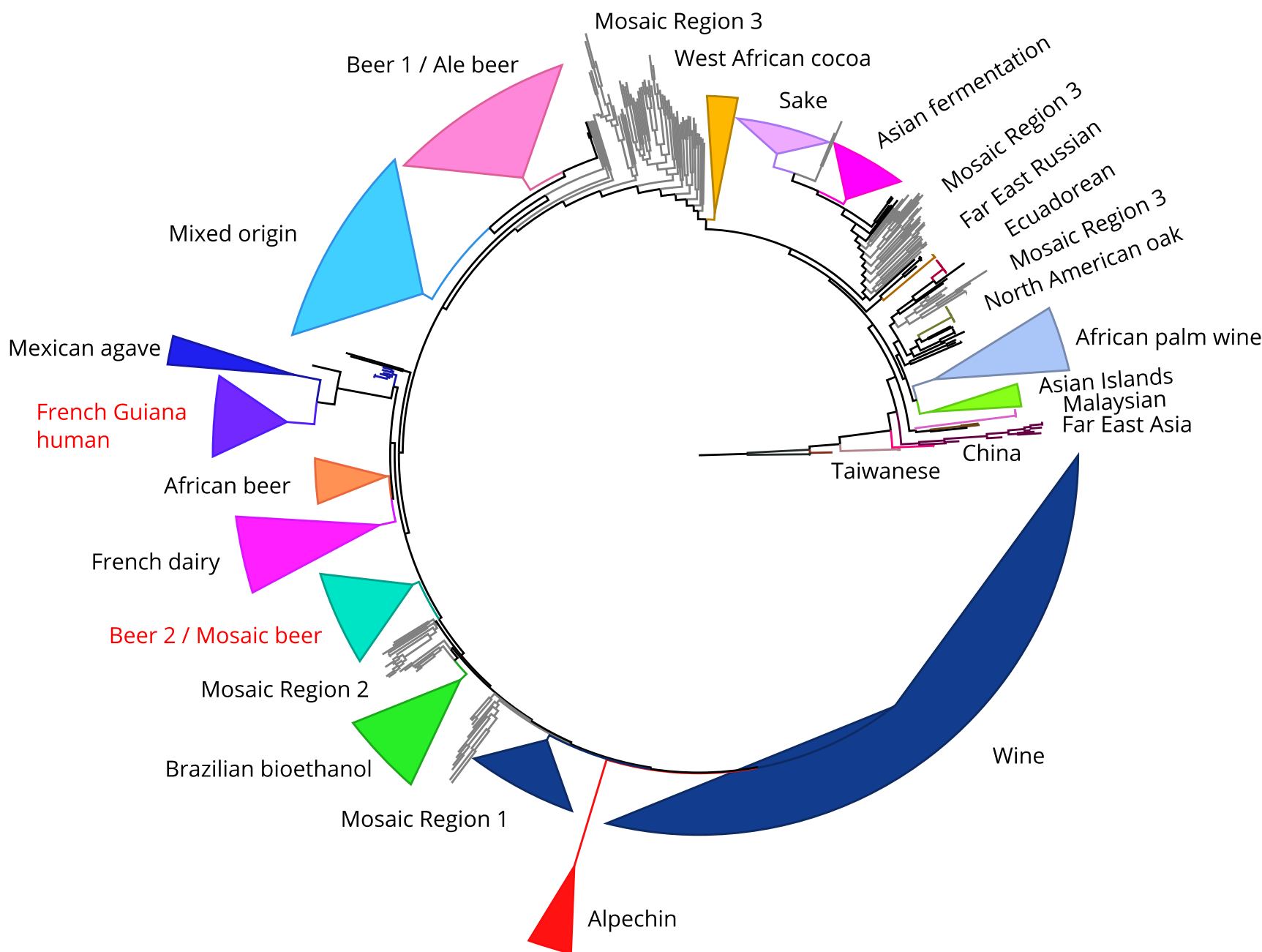

Fig. 2 The prevalence of the STA1 gene in 1171 publically available Saccharomyces cerevisiae genome assemblies (adapted from Krogerus et al. 2019). Clades have been collapsed to improve clarity and the names of clades containing STA1+ strains are colored red ('French Guiana human', and 'Beer 2\%/Mosaic beer'). The majority of the strains in both these clades contain STA1. The 'Beer 2' clade contains both strains isolated from contaminated beer and production strains used in commercial breweries use differs between the 'Beer 2' and the 'Beer 1' strains. The 'Beer 1' strains rely on transmembrane transport of maltotriose with the Agtlp permease, while 'Beer 2' strains carry frameshift mutations in the AGT1/MAL11 gene (Vidgren et al. 2005; Alves et al. 2008; Duval et al. 2010; Gallone et al. 2016). 'Beer 2' strains rather appear to rely on extracellular hydrolysis by the Stalp glucoamylase for maltotriose use. When STA1 was deleted from three diastatic strains, maltotriose consumption during wort fermentations decreased significantly (Krogerus et al. 2019). Furthermore, strains carrying the 1162-bp deletion in the STA1 promoter exhibit significantly slower maltotriose use during wort fermentations (Gallone et al. 2016; Krogerus et al. 2019). Despite extracellular hydrolysis appearing to be the dominant route of maltotriose use in diastatic strains, all three diastatic strains that were tested by Krogerus et al. (2019) still showed low transmembrane transport rates of maltotriose. This confirms that a maltotriose-transporting permease other than Agtlp is present in these strains.

Maltotriose use in brewing yeast is often considered a signature of domestication, as this sugar is fairly unique to brewer's wort in comparison with other beverage fermentation media, and the trait is rarely found in wild yeast (Gallone et al. 2016; Gonçalves et al. 2016; Steensels et al. 2019). While this trait has previously only been attributed to maltotriosetransporting permeases, the formation and retention of the STA1 gene appears to be an alternative evolutionary mechanism for enabling efficient use of sugars present in brewer's wort. STA1+ strains have likely been selected for as they are expected to have a competitive advantage in the beer environment. In addition, brewers may have inadvertently selected for these strains as they produce beer with a dry finish and mouthfeel (e.g., 'Saison'-style beer). The diastatic trait was probably later selected against, e.g., exemplified by the spread of the 
1162-bp deletion in the STA1 promoter, which leads to a considerable decrease in expression (Krogerus et al. 2019). This counter-selection may have been driven by the desired specifications of the beer (e.g., not overly dry) or the need to store beer for extended periods without excessive buildup of pressure in vessels.

Interestingly, the STA1 gene is also prevalent in strains belonging to the 'French Guiana human' population (Peter et al. 2018; Krogerus et al. 2019). These strains have been isolated from various origins including fruits, animals, and mainly human feces in a remote village in French Guiana (Angebault et al. 2013). None of these strains have been linked to beer contamination. However, a traditional starchrich fermented beverage called cachiri is produced and consumed in the village (La Barre 1938; Carrizales et al. 1986). It is likely that this starch-rich environment has been selected for diastatic strains. The evolutionary relationship between the 'Beer 2' and 'French Guiana human' strains remains unclear, but sequence similarity of STA1 and common polymorphisms compared with FLO11 in strains from the two populations suggest that STA1 originates from a common gene fusion event. Population structure analysis based on single nucleotide polymorphisms, suggests that the 'French Guiana human' population is a clean lineage, but the 'Beer 2' strains show evidence of admixture, particularly from South American bioethanol strains (Peter et al. 2018). However, the admixture analysis revealed no contribution from the 'French Guiana human' population in the 'Beer 2' strains, and further study around this topic is required.

The STAl gene has also been found in various Saccharomyces interspecies hybrids. A S. cerevisiae $\times$ Saccharomyces uvarum hybrid, 'Muri,' that was isolated from a traditional Norwegian farmhouse brewing yeast culture was shown to possess STA1 (Krogerus et al. 2018). Whole-genome sequencing revealed that the $S$. cerevisiae parent strain of this hybrid belonged to the 'Beer 2' lineage. A genetically very similar hybrid, WLP351, was also recently identified, and it is possible that it is the same strain (Langdon et al. 2019). STA1 is also present in the $S$. cerevisiae sub-genomes of various S. cerevisiae $\times$ Saccharomyces kudriavzevii hybrids that have been isolated from beer (Gallone et al. 2019). Again, the $S$. cerevisiae parent strains of these hybrids belong to the 'Beer 2' lineage.

In addition to enabling the utilization of longer chain carbohydrates, Sta1p also contributes to flocculation (Lo and Dranginis 1996). Deletion of STAl from a diastatic $S$. cerevisiae strain decreased flocculation ability, but not to the same extent as deletion of FLO11 from the same strain. It is likely that this flocculating activity results from interactions between Sta1p and Flo11p, as flocculins like Flo11p are known to form aggregates (Douglas et al. 2007). Like most brewers' yeasts, many of the STA1+ 'Beer 2' strains exhibit high levels of flocculation, which is typically a desired trait in brewery fermentations (Gallone et al. 2016).

\section{Detection of diastatic yeast in the brewery}

As diastatic yeast can have considerable negative impacts on beer quality, it is vital that they can be rapidly and reliably detected within the brewery. As they are genetically and physiologically similar to brewing strains, it can be difficult to distinguish contaminants from production strains. Detection methods for beer spoilage yeast can broadly be divided into traditional growth-based methods, and modern molecular methods (Powell and Kerruish 2017). The growth-based methods rely on culturing samples on selective media that either promote the growth of the spoilage yeast or prevent the growth of the production yeast (Fig. 3). Because of their simplicity and low cost, these methods are widely used in the brewing industry. However, they typically require a long time before results are available (sometimes weeks) and may generate false positives depending on the selective media.

In the case of diastatic $S$. cerevisiae, copper-containing media are often used for detection. Such media include LCSM (Lin's Cupric Sulphate Medium) and MYGP+copper (Malt extract, Yeast extract, Glucose, and Peptone media with copper) (Lin 1981; Taylor and Marsh 1984; van der Aa Kühle 1998). Ale and lager strains of S. cerevisiae are usually copper-sensitive and are unable to grow on these media, while diastatic S. cerevisiae strains are copper-tolerant. This tolerance has been linked to elevated copy numbers of the CUP1 locus (Zhao et al. 2014; Peter et al. 2018). However, as selection is based on copper tolerance, rather than diastatic ability, there is a potential for false positives. Wine strains of S. cerevisiae, for example, also tend to exhibit high copper tolerance (see Supplementary Fig. S2; Peter et al. 2018). Media containing starch or maltodextrin as the only fermentable carbon source have also been developed (MeierDörnberg et al. 2018; Burns et al. 2020). Diastatic strains can grow on these media thanks to their glucoamylolytic activity. To aid with evaluation, a $\mathrm{pH}$ indicator such as bromophenol blue or bromocresol green can be added to the media, so that growth is accompanied by a color change. Iodine can also be used to stain residual oligosaccharides in the growth media (Burns et al. 2020). However, growth is typically very slow on starch-containing agar, often requiring several weeks, and plates should ideally be incubated anaerobically to reduce the amount of false positives (MeierDörnberg et al. 2018). Durham tubes containing beer as growth media have also been used successfully to detect diastatic S. cerevisiae (Meier-Dörnberg et al. 2018). For these, a sample of yeast is inoculated into sterilized beer inside a Durham tube, and carbon dioxide production is monitored by the buildup of gas in the inverted inner tube. As with the agar-based methods, this method can also be time-consuming. 
Growth-based

detection methods

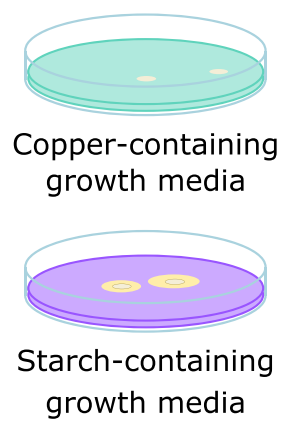

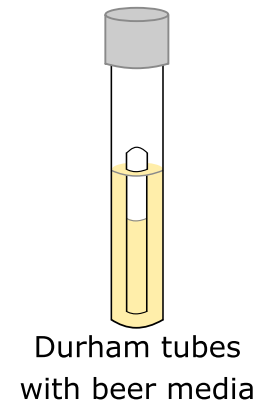

Molecular

detection methods

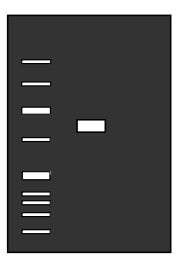

End-point PCR

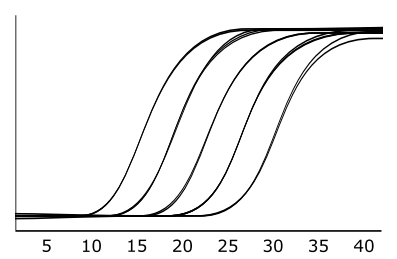

Quantitative PCR

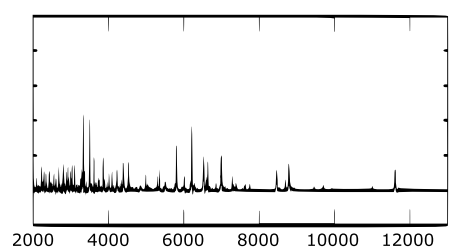

MALDI-TOF mass spectrometry
Detection of the STA1

gene and promoter

Fig. 3 A summary of detection methods available for the detection of diastatic S. cerevisiae in brewery samples. The methods can broadly be divided into growth-based and molecular methods

Various molecular detection methods have also been developed for the detection of diastatic S. cerevisiae (Fig. 3). Compared with the traditional growth-based methods, these are rapid and can give results in hours instead of days. The most widely used rely on the detection of the STA 1 gene using polymerase chain reaction (PCR), and several commercial kits are available. DNA is extracted from the yeast sample, and the SD-5A/SD-6B primer pair, for example, can be used to detect the presence of STA1 (Yamauchi et al. 1998). However, as was mentioned in the section on the regulation of STA1 transcription, not all strains possessing STA1 show spoilage potential, and this has been linked to a 1162-bp deletion in the STA1 promoter that significantly reduces expression of the gene (Krogerus et al. 2019). Primers for detecting this deletion in the $S T A 1$ promoter have also been developed and can be used in combination with the SD-5A/SD-6B primers to improve the reliability of detection. However, in a recent screen of 15 STA1+ strains from the Omega Yeast Labs collection, it was revealed that contamination of bottled beer with strains possessing the deletion in the promoter can still cause some refermentation in the bottle (Burns et al. 2020). Hence, a combination of a growth-based and PCR-based method is therefore recommended to accurately differentiate spoilage and non-spoilage STA1+ strains at the expense of time. Realtime or quantitative PCR systems have also been developed for the detection of the STA1 gene, and the further advantage of these is that lower detection levels can be achieved and the level of contamination can also be quantified (Brandl 2006; Meier-Dörnberg et al. 2018; Schönling et al. 2019). To improve (i.e., decrease) the detection limit of these methods, a pre-enrichment in selective growth media can also be applied to the yeast sample. In addition to these PCR-based methods, MALDI-TOF mass spectrometry has also been successfully applied to separate diastatic $S$. cerevisiae from brewing strains based on proteome mass spectra (Lauterbach et al. 2017). However, this method would likely not discriminate between closely related strains with and without the STA1 gene. While no immunoassays are, to our knowledge, available for the detection of diastatic $S$. cerevisiae, several such assays have been developed for the detection of other brewery contaminants (Nakakita et al. 2002). The direct detection of the Stalp glucoamylase from a beer or wort sample could yield another valuable approach to detecting diastatic $S$. cerevisiae contaminants.

\section{Industrial applications of diastatic yeast}

Despite their association with poor process hygiene and beer quality problems, diastatic strains of S. cerevisiae are considered to be acceptable production strains in specific cases. In such cases, the negative attributes of the group, i.e., overattenuation and production of the phenolic flavor note 4vinyl guaiacol, are considered positive features. In particular, diastatic strains are associated with saison-style beers, which have been growing in popularity for some years (RateBeer 2020). This farmhouse ale style, originating from Belgium, was traditionally brewed in autumn and stored until summer, when it was served to seasonal agricultural workers (saisonniers) as refreshment (Markowski 2004). Like other farmhouse ale beers not traditionally brewed for commercial purposes, the saison style is only loosely defined and there is no clear consensus regarding strength, flavor or color of the traditional saison forms. However, the modern saison is typified at least by a dry mouthfeel and spicy, phenolic character. Commercial saison starter cultures are usually diastatic strains of $S$. cerevisiae carrying the STA1 gene.

The acceptability of diastatic $S$. cerevisiae strains is clearly dependent on the brewing context, suggesting that, under controlled conditions, their use may be helpful in developing new flavor profiles for beers. With this in mind, Meier-Dörnberg et al. (2018) carried out a comprehensive evaluation of the brewing properties of multiple diastatic strains. Many of these strains were found to possess positive characteristics from a brewing perspective. These included strong flocculation and 
varied ability to utilize fermentable sugars and dextrins. All strains were found to produce a phenolic note, but in sensory trials, this property was not over-powering and beers produced were considered to be acceptable. Interestingly, the yeasts differed among each other and in relation to a reference strain with respect to flavor profile. Many showed strong fruit flavors, with tropical flavors being notable in some beers. Likewise, of the 157 S. cerevisiae strains studied by Gallone et al. (2016), the strains in the 'Beer 2' clade were consistently among the top producers of several flavor-active esters, typically producing more than the 'Beer 1' strains (Supplementary Fig. S3). Results suggest that the genetic diversity seen within the group could be used profitably for the creation of new beers, assuming the cultures are properly handled to reduce risk of contamination. The use of diastatic strains of $S$. cerevisiae in co-culture fermentations or in controlled secondary fermentations could likewise be used to add character to beer.

The phenolic flavor compound 4-vinylguaiacol is associated with beers produced with diastatic $S$. cerevisiae strains (Russell et al. 1983) - a feature that is not negative per se, but which limits the general applicability of these strains. For example, the popular 'M' strain whiskey yeast is believed to be a hybrid resulting from a cross with a diastatic yeast contaminant and, as a result, produces 4 -vinyl guaiacol. The phenolic flavor is however expected to be reduced during distillation, thereby negating the influence of the phenotype (Pauley and Maskell 2017). In beer, and particularly in lager beer, phenolic flavor notes can negatively influence the acceptability of the product. Indeed, many ale and lager strains lack the ability to produce phenolic off-flavors as a result of loss-of-function mutations in PADl or FDCl, two genes which are essential for the phenolic off-flavor phenotype (Mukai et al. 2014; Gallone et al. 2016). Non-phenolic strains with diastatic potential would be more appealing to brewers interested in creating beers that have a dry mouthfeel, or which can be promoted as low-calorie beverages. Recent studies have indeed revealed that some phenolic off-flavor negative (POF-) strains exist among the commercially available STA1+ strains (Gallone et al. 2016; Krogerus et al. 2019). This need also inspired Tubb et al. (1981) to create diastatic/phenolic off-flavor negative (STA1+/POF-) strains through the use of rare mating. The procedure involved crossing a STA $1+/ \mathrm{POF}+$ strain with a STA1-/POF - to create a heterozygous strain containing all parental alleles, and which could subsequently by sporulated to create a STA1+/POF- strain through meiotic segregation. The same approach has been used recently to create POF- Saccharomyces hybrids from diverse parents (Krogerus et al. 2017; Nikulin et al. 2018). The strain developed by Tubb et al. (1981), had some limitations. In particular, only about $25 \%$ of beer dextrin was utilized, a result attributed to an inability of the enzyme to act on dextrin $\alpha-1,6$ branch points. Also, the enzyme was active only relatively late in the fermentation. It was suggested by the authors that genetic engineering approaches could be more effective in introducing the diastatic trait without any negative effect on performance or product quality. Indeed, this approach was pursued actively in subsequent years, with several studies demonstrating the efficacy of introducing dextrin-degrading enzymes to production yeast. These included enzymes produced by genes derived from diastatic $S$. cerevisiae (Sakai et al. 1989; LatorreGarcía et al. 2008), but also from Aspergillus spp., Debaryomyces occidentalis, Lipomyces spp., and Schwanniomyces occidentalis (Cole et al. 1988; Lancashire et al. 1989; Gopal and Hammond 1992; la Grange-Nel et al. 2004; Wang et al. 2012; Park et al. 2014). The strain created by Gopal and Hammond (1992) has arguably been the most effective, with production-scale trials showing good fermentation performance, high attenuation, and acceptable flavor profile. The strain was the first to be approved for use in preparation of food for human consumption, but has never been applied industrially due to the continued consumer skepticism regarding GMO use in foods (Hammond 1995).

For the foreseeable future, brewers that wish to utilize diastatic yeasts, but prefer to avoid the phenolic phenotype may be limited to more 'natural' approaches to strain development. In addition to the hybridization and genetic segregation approach taken by Tubb et al. (1981), brewers could obtain diastatic yeasts from their own process lines or from other fermentation systems (Troilo et al. 2020). The phenolic phenotype could then be eliminated from these yeasts through, for example, UV mutagenesis and screening, as has been successfully demonstrated for the wild yeast $S$. eubayanus (Diderich et al. 2018).

The ability of diastatic strains of $S$. cerevisiae to utilize dextrin is relevant not only to brewing, but to any fermentation process involving starchy raw materials. Starch is a popular substrate for bioethanol production due to its abundance and low cost, especially when derived from agricultural or industrial residues (Balat and Balat 2009). This material does, however, need to be converted to fermentable sugars to enable fermentation. An obvious advantage of diastatic $S$. cerevisiae strains is that some costs associated with the use of exogenous enzymes may be reduced. While not the only yeast group expressing glucoamylase activity, these yeasts have the additional advantage of belonging to a species associated with high and consistent productivity, resistance to ethanol toxicity and osmotolerance. Indeed, diastatic $S$. cerevisiae strains are routinely isolated from bioethanol fermentation processes as well as other processes, including brewing, that utilize starch as a starting material (Laluce and Mattoon 1984; Troilo et al. 2020). Early studies showed that these strains had good potential for bioethanol production, either in pure culture (Laluce and Mattoon 1984; Amin et al. 1985) or co-culture (Amutha and Gunasekaran 2001). A limitation of the STA1-encoded glucoamylase is its lack of a 
starch-binding domain (Latorre-García et al. 2005), meaning that it has little ability to degrade raw, non-soluble starch, even when over-expressed (Nakamura et al. 1997). This limitation has been resolved by fusing the STA1 gene with the starchbinding domain of an Aspergillus niger glucoamylase gene, and expression of the gene fusion in S. cerevisiae (LatorreGarcía et al. 2005). Despite this improvement in productivity, there are other limitations, such as weak debranching activity of the enzyme (Nakamura et al. 1999). Accordingly, most attempts to engineer $S$. cerevisiae strains for glucoamylase production have involved introduction of genes from fungal species other than $S$. cerevisiae (Görgens et al. 2015). The STA1 signal peptide that mediates the extracellular expression of the enzyme has however been exploited for the expression of other hydrolytic enzymes such as $\alpha$-amylase, cellobiohydrolase, and $\beta$-glucosidase (Nam et al. 1994; Kang et al. 1996; Marín-Navarro et al. 2011; Gurgu et al. 2011; Gurgu et al. 2013).

\section{Conclusions}

Interest towards diastatic $S$. cerevisiae has increased in recent years. This results from an increase in the number of reported contaminations, and an increase in the popularity of specialty beers. These strains have traditionally been associated with beer spoilage, particularly in the lager brewing industry, and they can cause significant quality issues in the case of contamination. However, at the same time, diastatic strains have also inadvertently been used as production strains in many breweries. Indeed, with the increasing availability of wholegenome sequence data from brewing strains, it has been revealed that diastatic $S$. cerevisiae are widespread in the 'Beer 2' or 'Mosaic beer' population, and there is little genetic distinction between contaminant and production strains. The positive traits of diastatic $S$. cerevisiae strains may have been unfairly overlooked in the past decades due to their status as spoilage yeasts. Recent studies have shown that these strains possess desirable brewing properties, particularly a high formation of flavor-active esters, and could be used for strain and product development. In addition, from an evolutionary perspective, diastatic strains offer insight on mechanisms used for adaptation to fermentation environments. The formation and retention of the chimeric STA1 gene, which causes the diastatic phenotype, not only enables dextrin fermentation, but appears to be the main mechanism for maltotriose use in diastatic S. cerevisiae. This is in contrast to ale and lager brewing strains, which use the Agtlp permease to transport maltotriose into the cell. Interestingly, STA1 is also found in multiple strains that were isolated from a remote village in French Guiana. Future studies still need to clarify the origin of STA1 and the relatedness of STA1+ strains. To conclude, the resurgence of interest in diastatic $S$. cerevisiae has been inspired by this group's negative attributes, but has fortuitously revealed many positive traits that can be exploited profitably by the brewing industry.

Author contributions $\mathrm{KK}$ and BG planned and wrote the manuscript. Both authors read and approved the manuscript.

Funding Information Open access funding provided by Technical Research Centre of Finland (VTT).

\section{Compliance with ethical standards}

Conflict of interest Both authors are employed by VTT Technical Research Centre of Finland Ltd. The funders had no role in study design, data collection and analysis, decision to publish, or preparation of the manuscript.

Ethics statement This article does not contain any studies with human participants or animals by any of the authors.

Open Access This article is licensed under a Creative Commons Attribution 4.0 International License, which permits use, sharing, adaptation, distribution and reproduction in any medium or format, as long as you give appropriate credit to the original author(s) and the source, provide a link to the Creative Commons licence, and indicate if changes were made. The images or other third party material in this article are included in the article's Creative Commons licence, unless indicated otherwise in a credit line to the material. If material is not included in the article's Creative Commons licence and your intended use is not permitted by statutory regulation or exceeds the permitted use, you will need to obtain permission directly from the copyright holder. To view a copy of this licence, visit http://creativecommons.org/licenses/by/4.0/.

\section{References}

Adam AC, Latorre-García L, Polaina J (2004) Structural analysis of glucoamylase encoded by the STA1 gene of Saccharomyces cerevisiae (var. diastaticus). Yeast 21:379-388. https://doi.org/10. 1002/yea.1102

Alves S Jr, Herberts R, Hollatz C, Trichez D, Miletti L, de Araujo P, Stambuk B (2008) Molecular analysis of maltotriose active transport and fermentation by Saccharomyces cerevisiae reveals a determinant role for the AGT1 permease. Appl Environ Microbiol 74: 1494-1501. https://doi.org/10.1128/AEM.02570-07

Amin G, De Mot R, Van Dijck K, Verachtert H (1985) Direct alcoholic fermentation of starchy biomass using amylolytic yeast strains in batch and immobilized cell systems. Appl Microbiol Biotechnol 22:237-245. https://doi.org/10.1007/BF00252023

Amutha R, Gunasekaran P (2001) Production of ethanol from liquefied cassava starch using co-immobilized cells of Zymomonas mobilis and Saccharomyces diastaticus. J Biosci Bioeng 92:560-564. https://doi.org/10.1016/S1389-1723(01)80316-9

Andrews BJ, Gilliland RB (1952) Super-attenuation of beer: a study of three organisms capable of causing abnormal attenuations. J Inst Brew 58:189-196. https://doi.org/10.1002/j.2050-0416.1952. tb02675.x

Angebault C, Djossou F, Abélanet S, Permal E, Ben Soltana M, Diancourt L, Bouchier C, Woerther P-L, Catzeflis F, Andremont A, D'Enfert C, Bougnoux M-E (2013) Candida albicans is not always the preferential yeast colonizing humans: a study in 
Wayampi Amerindians. J Infect Dis 208:1705-1716. https://doi.org/ 10.1093/infdis/jit389

Balat M, Balat H (2009) Recent trends in global production and utilization of bio-ethanol fuel. Appl Energy 86:2273-2282. https://doi.org/ 10.1016/j.apenergy.2009.03.015

Barrales RR, Jimenez J, Ibeas JI (2008) Identification of novel activation mechanisms for FLO11 regulation in Saccharomyces cerevisiae. Genetics 178:145-156. https://doi.org/10.1534/genetics.107. 081315

Begrow W (2017) Fighting quality threats: notable microbiological contaminations of craft beer in the United States. Brew Beverage Ind Int:10-13

Bignell GR, Evans IH (1990) Localization of glucoamylase genes of Saccharomyces cerevisiae by pulsed field gel electrophoresis. Antonie Van Leeuwenhoek 58:49-55. https://doi.org/10.1007/BF02388079

Bishop LR, Whitley WA (1943) A system of wort analysis. J Inst Brew 49:223-235. https://doi.org/10.1002/j.2050-0416.1943.tb01241.x

Brandl A (2006) Entwicklung und Optimierung von PCR-Methoden zur Detektion und Identifizierung von brauereirelevanten Mikroorganismen zur Routine-Anwendung in Brauereien. Technische Universität München

Brouwers N, Gorter de Vries AR, van den Broek M, Weening SM, Elink Schuurman TD, Kuijpers NGA, Pronk JT, Daran J-MG (2019) In vivo recombination of Saccharomyces eubayanus maltosetransporter genes yields a chimeric transporter that enables maltotriose fermentation. PLoS Genet 15:e1007853. https://doi. org/10.1371/journal.pgen.1007853

Brown CA, Murray AW, Verstrepen KJ (2010) Rapid expansion and functional divergence of subtelomeric gene families in yeasts. Curr Biol 20:895-903. https://doi.org/10.1016/j.cub.2010.04.027

Brückner S, Mösch H-U (2012) Choosing the right lifestyle: adhesion and development in Saccharomyces cerevisiae. FEMS Microbiol Rev 36:25-58. https://doi.org/10.1111/j.1574-6976.2011.00275.x

Burns L, Sislak C, Gibbon N, Saylor N, Seymour M, Shaner L, Gibney P (2020) Improved functional assays and risk assessment for STA1+ strains of Saccharomyces cerevisiae. J Am Soc Brew Chem. Under review. Available at: https://omegayeast.com/uploads/downloads/ functional-assays-diastaticus.pdf

Carrizales V, Barrios O, González J (1986) Mejoramiento tecnológico de la producción de cachiri bebida fermentada de yuca (Manihot esculenta Crantz) de origen indígena. Acta Cient Venez 37:318-324

Cole GE, McCabe PC, Inlow D, Gelfand DH, Ben-Bassat A, Innis MA (1988) Stable expression of Aspercillus awamori glucoamylase in distiller's yeast. Nat Biotechnol 6:417-421. https://doi.org/10.1038/ nbt0488-417

Cullen PJ, Sprague GF (2012) The regulation of filamentous growth in yeast. Genetics 190:23-49. https://doi.org/10.1534/genetics.111.127456

Day RE, Rogers PJ, Dawes IW, Higgins VJ (2002) Molecular analysis of maltotriose transport and utilization by Saccharomyces cerevisiae. Appl Environ Microbiol 68:5326-5335. https://doi.org/10.1128/ AEM.68.11.5326-5335.2002

Diderich JA, Weening SM, van den Broek M, Pronk JT, Daran J-MG (2018) Selection of Pof-Saccharomyces eubayanus variants for the construction of S. cerevisiae $\times$ S. eubayanus hybrids with reduced 4 vinyl guaiacol formation. Front Microbiol 9. https://doi.org/10. 3389/fmicb.2018.01640

Douglas LM, Li L, Yang Y, Dranginis AM (2007) Expression and characterization of the flocculin Flo11/Muc1, a Saccharomyces cerevisiae mannoprotein with homotypic properties of adhesion. Eukaryot Cell 6:2214-2221. https://doi.org/10.1128/EC.00284-06

Dranginis AM (1989) Regulation of STA1 gene expression by MAT during the life cycle of Saccharomyces cerevisiae. Mol Cell Biol 9: 3992-3998. https://doi.org/10.1128/MCB.9.9.3992

Dunn B, Paulish T, Stanbery A, Piotrowski J, Koniges G, Kroll E, Louis EJ, Liti G, Sherlock G, Rosenzweig F (2013) Recurrent rearrangement during adaptive evolution in an interspecific yeast hybrid suggests a model for rapid introgression. PLoS Genet 9:e1003366. https://doi.org/10.1371/journal.pgen.1003366

Duval E, Alves S Jr, Dunn B, Sherlock G, Stambuk B (2010) Microarray karyotyping of maltose-fermenting Saccharomyces yeasts with differing maltotriose utilization profiles reveals copy number variation in genes involved in maltose and maltotriose utilization. J Appl Microbiol 109: 248-259. https://doi.org/10.1111/j.1365-2672.2009.04656.x

Erratt JA, Nasim A (1986) Allelism within the DEX and STA gene families in Saccharomyces diastaticus. MGG Mol Gen Genet 202:255256. https://doi.org/10.1007/BF00331646

Erratt JA, Stewart GG (1981) Genetic and biochemical studies on glucoamylase from Saccharomyces diastaticus. In: Advances in Biotechnology. Elsevier, pp 177-183

François J, Parrou J-L (2001) Reserve carbohydrates metabolism in the yeast Saccharomyces cerevisiae. FEMS Microbiol Rev 25:125-145. https://doi.org/10.1016/S0168-6445(00)00059-0

Gagiano M, Van Dyk D, Bauer FF, Lambrechts MG, Pretorius IS (1999) Divergent regulation of the evolutionarily closely related promoters of the Saccharomyces cerevisiae STA2 and MUC1 genes. J Bacteriol 181:6497-6508

Gallone B, Steensels J, Prahl T, Soriaga L, Saels V, Herrera-Malaver B, Merlevede A, Roncoroni M, Voordeckers K, Miraglia L, Teiling C, Steffy B, Taylor M, Schwartz A, Richardson T, White C, Baele G, Maere S, Verstrepen KJ (2016) Domestication and divergence of Saccharomyces cerevisiae beer yeasts. Cell 166:1397-1410.e16. https://doi.org/10.1016/j.cell.2016.08.020

Gallone B, Steensels J, Mertens S, Dzialo MC, Gordon JL, Wauters R, Theßeling FA, Bellinazzo F, Saels V, Herrera-Malaver B, Prahl T, White C, Hutzler M, Meußdoerffer F, Malcorps P, Souffriau B, Daenen L, Baele G, Maere S, Verstrepen KJ (2019) Interspecific hybridization facilitates niche adaptation in beer yeast. Nat Ecol Evol 3:1562-1575. https://doi.org/10.1038/s41559-019-0997-9

Gilliland RB (1966) Saccharomyces diastaticus-a starch-fermenting yeast. J Inst Brew 72:271-275. https://doi.org/10.1002/j.20500416.1966.tb02964.x

Gonçalves M, Pontes A, Almeida P, Barbosa R, Serra M, Libkind D, Hutzler M, Gonçalves P, Sampaio JP (2016) Distinct domestication trajectories in top-fermenting beer yeasts and wine yeasts. Curr Biol 26:2750-2761. https://doi.org/10.1016/j.cub.2016.08.040

Gopal C, Hammond J (1992) Use of genetically-modified yeasts for beer production. Eur Brew Conv Proc Congr, In, pp 297-306

Görgens JF, Bressler DC, van Rensburg E (2015) Engineering Saccharomyces cerevisiae for direct conversion of raw, uncooked or granular starch to ethanol. Crit Rev Biotechnol 35:369-391. https://doi.org/10.3109/07388551.2014.888048

Gurgu L, Lafraya Á, Polaina J, Marín-Navarro J (2011) Fermentation of cellobiose to ethanol by industrial Saccharomyces strains carrying the $\beta$-glucosidase gene (BGL1) from Saccharomycopsis fibuligera. Bioresour Technol 102:5229-5236. https://doi.org/10.1016/j. biortech.2011.01.062

Gurgu L, Barbu V, Dinică R (2013) Studies about expression of CbhB encoding gene from Aspergillus niger into Saccharomyces cerevisiae. Rom Biotechnol Lett 18:7975-7982

Hammond JRM (1995) Genetically-modified brewing yeasts for the 21st century. Progress to date. Yeast 11:1613-1627. https://doi.org/10. 1002/yea.320111606

Kang DO, Hwang IK, Kim BY, Ahn SC, Mheen TI, Ahn JS, Byun SM (1996) Secretion of Bacillus $\alpha$-amylase from yeast directed by glucoamylase I signal sequence of Saccharomyces diastaticus. IUBMB Life 39:181-190. https://doi.org/10.1080/ 15216549600201181

Kim TS, Ahn JY, Yoon JH, Kang HS (2003) STA10 repression of STA gene expression is caused by a defective activator, flo 8 , in Saccharomyces cerevisiae. Curr Genet 44:261-267. https://doi.org/ 10.1007/s00294-003-0447-7 
Kim TS, Kim HY, Yoon JH, Kang HS (2004a) Recruitment of the Swi/ Snf complex by Ste12-Tec1 promotes Flo8-Mss11-mediated activation of STA1 expression. Mol Cell Biol 24:9542-9556. https://doi. org/10.1128/MCB.24.21.9542-9556.2004

Kim TS, Lee SB, Kang HS (2004b) Glucose repression of STA1 expression is mediated by the Nrg1 and Sfl1 repressors and the Srb8-11 complex. Mol Cell Biol 24:7695-7706. https://doi.org/10.1128/ MCB.24.17.7695-7706.2004

Kleinman MJ, Wilkinson AE, Wright IP, Evans IH, Bevan EA (1988) Purification and properties of an extracellular glucoamylase from a diastatic strain of Saccharomyces cerevisiae. Biochem J 249:163170. https://doi.org/10.1042/bj2490163

Krogerus K, Seppänen-Laakso T, Castillo S, Gibson B (2017) Inheritance of brewing-relevant phenotypes in constructed Saccharomyces cerevisiae x Saccharomyces eubayanus hybrids. Microb Cell Factories 16:66. https://doi.org/10.1186/s12934-017-0679-8

Krogerus K, Preiss R, Gibson B (2018) A unique Saccharomyces cerevisiae $\times$ Saccharomyces uvarum hybrid isolated from Norwegian farmhouse beer: characterization and reconstruction. Front Microbiol 9. https://doi.org/10.3389/fmicb.2018.02253

Krogerus K, Magalhães F, Kuivanen J, Gibson B (2019) A deletion in the STA1 promoter determines maltotriose and starch utilization in STA1+ Saccharomyces cerevisiae strains. Appl Microbiol Biotechnol 103: 7597-7615. https://doi.org/10.1007/s00253-019-10021-y

La Barre W (1938) Native American beers. Am Anthropol 40:224-234. https://doi.org/10.1525/aa.1938.40.2.02a00040

La Grange-Nel K, Smit A, Otero RRC, Lambrechts MG, Willemse Q, Rensburg P, Pretorius IS (2004) Expression of 2 Lipomyces kononenkoae $\alpha$-amylase genes in selected whisky yeast strains. J Food Sci 69:175-181. https://doi.org/10.1111/j.1365-2621.2004. tb13617.x

Laluce C, Mattoon JR (1984) Development of rapidly fermenting strains of Saccharomyces diastaticus for direct conversion of starch and dextrins to ethanol. Appl Environ Microbiol 48:17-25

Lambrechts MG, Pretorias IS, Sollitti P, Marmur J (1991) Primary structure and regulation of a glucoamylase-encoding gene (STA2) in Saccharomyces diastaticus. Gene 100:95-103. https://doi.org/10. 1016/0378-1119(91)90354-E

Lambrechts MG, Pretorius IS, D’Aguanno VS, Sollitti P, Marmur J (1994) Multiple positive and negative cis-acting elements of the STA2 gene regulate glucoamylase synthesis in Saccharomyces cerevisiae. Gene 146:137-144. https://doi.org/10.1016/0378-1119(94)90286-0

Lancashire W, Carter A, Howard J, Wilde R (1989) Super-attenuating brewing yeast. In: Eur Brew Conv Proc Congr, pp 491-498

Langdon QK, Peris D, Baker EP, Opulente DA, Nguyen H-V, Bond U, Gonçalves P, Sampaio JP, Libkind D, Hittinger CT (2019) Fermentation innovation through complex hybridization of wild and domesticated yeasts. Nat Ecol Evol 3:1576-1586. https://doi. org/10.1038/s41559-019-0998-8

Latorre-García L, Adam AC, Manzanares P, Polaina J (2005) Improving the amylolytic activity of Saccharomyces cerevisiae glucoamylase by the addition of a starch binding domain. J Biotechnol 118:167176. https://doi.org/10.1016/j.jbiotec.2005.03.019

Latorre-García L, Adam AC, Polaina J (2008) Overexpression of the glucoamylase-encoding STA1 gene of Saccharomyces cerevisiae var. diastaticus in laboratory and industrial strains of Saccharomyces. World J Microbiol Biotechnol 24:2957-2963. https://doi.org/10.1007/s11274-008-9837-9

Lauterbach A, Usbeck JC, Behr J, Vogel RF (2017) MALDI-TOF MS typing enables the classification of brewing yeasts of the genus Saccharomyces to major beer styles. PLoS One 12:e0181694. https://doi.org/10.1371/journal.pone.0181694

Lin Y (1981) Formulation and testing of cupric sulphate medium for wild yeast detection. J Inst Brew 87:151-154. https://doi.org/10.1002/j. 2050-0416.1981.tb04005.x
Liti G, Carter DM, Moses AM, Warringer J, Parts L, James SA, Davey RP, Roberts IN, Burt A, Koufopanou V, Tsai IJ, Bergman CM, Bensasson D, O'Kelly MJT, van Oudenaarden A, Barton DBH, Bailes E, Nguyen AN, Jones M, Quail MA, Goodhead I, Sims S, Smith F, Blomberg A, Durbin R, Louis EJ (2009) Population genomics of domestic and wild yeasts. Nature 458:337-341. https://doi. org/10.1038/nature 07743

Lo WS, Dranginis AM (1996) FLO11, a yeast gene related to the STA genes, encodes a novel cell surface flocculin. J Bacteriol 178:71447151. https://doi.org/10.1128/jb.178.24.7144-7151.1996

Madhani HD (1997) Combinatorial control required for the specificity of yeast MAPK signaling. Science (80- ) 275:1314-1317. https://doi. org/10.1126/science.275.5304.1314

Marín-Navarro J, Gurgu L, Alamar S, Polaina J (2011) Structural and functional analysis of hybrid enzymes generated by domain shuffling between Saccharomyces cerevisiae (var. diastaticus) STA1 glucoamylase and Saccharomycopsis fibuligera Bgll $\beta$-glucosidase. Appl Microbiol Biotechnol 89:121-130. https://doi.org/10. 1007/s00253-010-2845-3

Markowski P (2004) Farmhouse ales: culture and craftsmanship in the Belgian tradition. Brewers Publications

Meier-Dörnberg T, Jacob F, Michel M, Hutzler M (2017) Incidence of Saccharomyces cerevisiae var. diastaticus in the beverage industry: cases of contamination, 2008-2017. Tech Q 54:140-148. https:// doi.org/10.1094/TQ-54-4-1130-01

Meier-Dörnberg T, Kory OI, Jacob F, Michel M, Hutzler M (2018) Saccharomyces cerevisiae variety diastaticus friend or foe? - spoilage potential and brewing ability of different Saccharomyces cerevisiae variety diastaticus yeast isolates by genetic, phenotypic and physiological characterization. FEMS Yeast Res 18. https://doi. org/10.1093/femsyr/foy023

Modena D, Vanoni M, Englard S, Marmur J (1986) Biochemical and immunological characterization of the STA2-encoded extracellular glucoamylase from Saccharomyces diastaticus. Arch Biochem Biophys 248:138-150. https://doi.org/10.1016/0003-9861(86) 90410-8

Mukai N, Masaki K, Fujii T, Iefuhi H (2014) Single nucleotide polymorphisms of $P A D 1$ and $F D C 1$ show a positive relationship with ferulic acid decarboxylation ability among industrial yeasts used in alcoholic beverage production. J Biosci Bioeng 118:50-55. https://doi. org/10.1016/j.jbiosc.2013.12.017

Nakakita Y, Takahashi T, Tsuchiya Y, Watari J, Shinotsuka K (2002) A strategy for detection of all beer-spoilage bacteria. J Am Soc Brew Chem 60:63-67. https://doi.org/10.1094/ASBCJ-60-0063

Nakamura Y, Kobayashi F, Ohnaga M, Sawada T (1997) Alcohol fermentation of starch by a genetic recombinant yeast having glucoamylase activity. Biotechnol Bioeng 53:21-25. https://doi.org/10.1002/(SICI) 1097-0290(19970105)53:1<21::AID-BIT4>3.0.CO;2-0

Nakamura Y, Sawada T, Yamaguchi K (1999) Breeding and cultivation of glucoamylase-producing yeast with inactivation of MAT locus. J Chem Eng Japan 32:424-430. https://doi.org/10.1252/jcej.32.424

Nam SW, Kim BM, Chung BH, Kang DO, Ahn JS (1994) Expression and secretion of human lipocortin-1 by promoter and signal sequence of STA1 from Saccharomyces diastaticus. Biotechnol Lett 16:897-902. https://doi.org/10.1007/BF00128621

Nikulin J, Krogerus K, Gibson B (2018) Alternative Saccharomyces interspecies hybrid combinations and their potential for lowtemperature wort fermentation. Yeast 35:113-127. https://doi.org/ 10.1002/yea.3246

Octavio LM, Gedeon K, Maheshri N (2009) Epigenetic and conventional regulation is distributed among activators of FLO11 allowing tuning of population-level heterogeneity in its expression. PLoS Genet 5: e1000673. https://doi.org/10.1371/journal.pgen.1000673

Pan X, Heitman J (1999) Cyclic AMP-dependent protein kinase regulates pseudohyphal differentiation in Saccharomyces cerevisiae. Mol Cell Biol 19:4874-4887. https://doi.org/10.1128/MCB.19.7.4874 
Pardo JM, Polaina J, Jimènez A (1986) Cloning of the STA2 and SGA genes encoding glucoamylases in yeasts and regulation of their expression by the STA10 gene of Saccharomyces cerevisiae. Nucleic Acids Res 14:4701-4718. https://doi.org/10.1093/nar/14.12.4701

Park J-Y, Lee J-Y, Choi S-H, Ko H-M, Kim I-C, Lee HB, Bai S (2014) Construction of dextrin and isomaltose-assimilating brewer's yeasts for production of low-carbohydrate beer. Biotechnol Lett 36:16931699. https://doi.org/10.1007/s10529-014-1530-5

Pauley M, Maskell D (2017) Mini-review: the role of Saccharomyces cerevisiae in the production of gin and vodka. Beverages 3:13. https://doi.org/10.3390/beverages3010013

Peter J, De Chiara M, Friedrich A, Yue J-X, Pflieger D, Bergström A, Sigwalt A, Barre B, Freel K, Llored A, Cruaud C, Labadie K, Aury J-M, Istace B, Lebrigand K, Barbry P, Engelen S, Lemainque A, Wincker P, Liti G, Schacherer J (2018) Genome evolution across 1, 011 Saccharomyces cerevisiae isolates. Nature 556:339-344. https://doi.org/10.1038/s41586-018-0030-5

Polaina J, Wiggs MY (1983) STA10: a gene involved in the control of starch utilization by Saccharomyces. Curr Genet 7:109-112. https:// doi.org/10.1007/BF00365634

Powell CD, Kerruish DWM (2017) Beer-spoiling yeasts: genomics, detection, and control. In: brewing microbiology: current research, omics and microbial ecology. Caister Academic Press

Pretorius IS, Marmu J (1988) Localization of yeast glucoamylase genes by PFGE and OFAGE. Curr Genet 14:9-13. https://doi.org/10.1007/ BF00405847

Pretorius IS, Modena D, Vanoni M, Englard S, Marmur J (1986) Transcriptional control of glucoamylase synthesis in vegetatively growing and sporulating Saccharomyces species. Mol Cell Biol 6: 3034-3041. https://doi.org/10.1128/MCB.6.9.3034

Pugh TA, Shah JC, Magee PT, Clancy MJ (1989) Characterization and localization of the sporulation glucoamylase of Saccharomyces cerevisiae. Biochim Biophys Acta Protein Struct Mol Enzymol 994:200-209. https://doi.org/10.1016/0167-4838(89)90294-X

RateBeer (2020) RateBeer. https://www.ratebeer.com/

Rupp S, Summers E, Lo H-J, Madhani H, Fink G (1999) MAP kinase and cAMP filamentation signaling pathways converge on the unusually large promoter of the yeast FLO11 gene. EMBO J 18:1257-1269. https://doi.org/10.1093/emboj/18.5.1257

Russell I, Hancock IF, Stewart GG (1983) Construction of dextrin fermentative yeast strains that do not produce phenolic off-flavors in beer. J Am Soc Brew Chem 41:45-51. https://doi.org/10.1094/ASBCJ-41-0045

Sakai K, Fukui S, Yabuuchi S, Aoyagi S, Tsumura Y (1989) Expression of the Saccharomyces diastaticus STA1 gene in brewing yeasts. J Am Soc Brew Chem 47:87-91. https://doi.org/10.1094/ASBCJ-47-0087

Sauer J, Sigurskjold BW, Christensen U, Frandsen TP, Mirgorodskaya E, Harrison M, Roepstorff P, Svensson B (2000) Glucoamylase: structure/function relationships, and protein engineering. Biochim Biophys Acta Protein Struct Mol Enzymol 1543:275-293. https:// doi.org/10.1016/S0167-4838(00)00232-6

Schönling J, Pick E, Peter U, Britton S (2019) Effect of autolytic by-products on PCR-detection of beer spoilers in yeast slurry. BrewingScience 72: 168-172. https://doi.org/10.23763/BrSc19-18schoenling

Searle BA, Tubb RS (1981) Regulation of amyloglucosidase production by Saccharomyces diastaticus. J Inst Brew 87:244-247. https://doi. org/10.1002/j.2050-0416.1981.tb04025.x

Solovicova A, Christensen T, Hostinova E, Gasperik J, Sevcik J, Svensson B (1999) Structure-function relationships in glucoamylases encoded by variant Saccharomycopsis fibuligera genes. Eur J Biochem 264: 756-764. https://doi.org/10.1046/j.1432-1327.1999.00634.x

Steensels J, Gallone B, Voordeckers K, Verstrepen KJ (2019) Domestication of industrial microbes. Curr Biol 29:R381-R393. https://doi.org/10.1016/j.cub.2019.04.025

Tamaki H (1978) Genetic studies of ability to ferment starch in Saccharomyces: gene polymorphism. Mol Gen Genet 164:205209. https://doi.org/10.1007/BF00267385
Taylor GT, Marsh AS (1984) MYGP + copper, a medium that detects both Saccharomyces and non-Saccharomyces wild yeast in the presence of culture yeast*. J Inst Brew 90:134-145. https://doi.org/10. 1002/j.2050-0416.1984.tb04254.x

Troilo A, De Francesco G, Marconi O, Sileoni V, Turchetti B, Perretti G (2020) Low carbohydrate beers produced by a selected yeast strain from an alternative source. J Am Soc Brew Chem 78:80-88. https:// doi.org/10.1080/03610470.2019.1682887

Tubb RS, Searle BA, Goodey AR, Brown AJP (1981) Rare mating and transformation for construction of novel brewing yeasts. Proc. 18th Congr. Eur. Brew. Conv. 487-496

van der Aa Kühle A (1998) Detection and identification of wild yeasts in lager breweries. Int J Food Microbiol 43:205-213. https://doi.org/ 10.1016/S0168-1605(98)00113-5

Vanoni M, Porro D, Martegani E, Alberghina L (1989) Secretion of Escherichia coli $\beta$-galactosidase in Saccharomyces cerevisiae using the signal sequence from the glucoamylase-encoding STA2 gene. Biochem Biophys Res Commun 164:1331-1338. https://doi.org/ 10.1016/0006-291X(89)91815-9

Vidgren V, Ruohonen L, Londesborough J (2005) Characterization and functional analysis of the $M A L$ and $M P H$ loci for maltose utilization in some ale and lager yeast strains. Appl Environ Microbiol 71: 7846-7857. https://doi.org/10.1128/AEM.71.12.7846-7857.2005

Vinod PK, Sengupta N, Bhat PJ, Venkatesh KV (2008) Integration of global signaling pathways, cAMP-PKA, MAPK and TOR in the regulation of FLO11. PLoS One 3:e1663. https://doi.org/10.1371/ journal.pone. 0001663

Wang J-J, Wang Z-Y, He X-P, Zhang B-R (2012) Integrated expression of the $\alpha$-amylase, dextranase and glutathione gene in an industrial brewer's yeast strain. World J Microbiol Biotechnol 28:223-231. https://doi.org/10.1007/s11274-011-0811-6

Yamashita I (1989) The theonine- and serine-rich tract of the secretory glucoamylase can direct beta-galactosidase to the cell envelope. Agric Biol Chem 53:483-489. https://doi.org/10.1271/bbb1961.53.483

Yamashita I, Maemura T, Hatano T, Fukui S (1985a) Polymorphic extracellular glucoamylase genes and their evolutionary origin in the yeast Saccharomyces diastaticus. J Bacteriol 161:574-582

Yamashita I, Suzuki K, Fukui S (1985b) Nucleotide sequence of the extracellular glucoamylase gene STA1 in the yeast Saccharomyces diastaticus. J Bacteriol 161:567-573

Yamashita I, Suzuki K, Fukui S (1986) Proteolytic processing of glucoamylase in the yeast Saccharomyces diastaticus. Agric Biol Chem 50:475-482. https://doi.org/10.1271/bbb1961.50.475

Yamashita I, Nakamura M, Fukui S (1987) Gene fusion is a possible mechanism underlying the evolution of STA1. J Bacteriol 169: 2142-2149. https://doi.org/10.1128/jb.169.5.2142-2149.1987

Yamauchi H, Yamamoto H, Shibano Y, Amaya N, Saeki T (1998) Rapid methods for detecting Saccharomyces diastaticus, a beer spoilage yeast, using the polymerase chain reaction. J Am Soc Brew Chem 56:58-63. https://doi.org/10.1094/ASBCJ-56-0058

Yue J-X, Li J, Aigrain L, Hallin J, Persson K, Oliver K, Bergström A, Coupland P, Warringer J, Lagomarsino MC, Fischer G, Durbin R, Liti G (2017) Contrasting evolutionary genome dynamics between domesticated and wild yeasts. Nat Genet 49:913-924. https://oi. org/10.1038/ng.3847

Zhao Y, Strope PK, Kozmin SG, McCusker JH, Dietrich FS, Kokoska RJ, Petes TD (2014) Structures of naturally evolved CUP1 tandem arrays in yeast indicate that these arrays are generated by unequal nonhomologous recombination. G3 Genes|Genomes|Genetics 4: 2259-2269. https://doi.org/10.1534/g3.114.012922

Publisher's note Springer Nature remains neutral with regard to jurisdictional claims in published maps and institutional affiliations. 